\title{
Inhibition of p53 alleviates prostate cell apoptosis in Escherichia coli-induced bacterial prostatitis
}

\author{
HAI WANG and ZHIGANG JI \\ Department of Urology, Peking Union Medical College Hospital, \\ Chinese Academy of Medical Science, Beijing 100730, P.R. China
}

Received May 17, 2018; Accepted December 21, 2018

DOI: $10.3892 / \mathrm{mmr} .2019 .10354$

\begin{abstract}
Previous studies demonstrated that uropathogenic Escherichia coli infection contributes to human bacterial prostatitis. Apoptosis of prostate epithelial cells is closely associated with the progression of bacterial prostatitis. The aim of the present study was to investigate the effect of cellular tumor antigen p53 (p53) on the apoptosis of bacterial prostatitis cells. The prostate epithelial RWPE-1 cell line was infected with Escherichia coli, and treated cells and the culture supernatant were obtained at specific time points. The cell apoptosis rates, protein and mRNA of p53 were detected in the different treatment groups. Flow cytometry and terminal deoxynucleotidyl-transferase-mediated dUTP nick end labeling assays were used for the detection of cell apoptosis, and cell proliferation was determined by a Cell Counting Kit- 8 assay. The expression of p53 was inhibited by small interfering (si)RNA, and its mRNA and protein were detected. An ELISA was used for detecting cytokines in the culture supernatant. The result demonstrated that Escherichia coli infection led to an increase in prostate epithelial cell apoptosis $(\mathrm{P}<0.05)$, and resulted in increases of interleukin (IL)-4, IL-6 and IL-8, and decrease in IL-10. p53, apoptosis regulator BAX (Bax), caspase-9 and Caspase-3 expression were upregulated upon Escherichia coli exposure $(\mathrm{P}<0.05)$. Following transfection with p53 siRNA, the promotion of cell apoptosis induced by Escherichia coli infection was decreased, and the p53 and Bax protein expression were additionally decreased. Therefore, it was suggested that Escherichia coli increases cell apoptosis in bacterial prostatitis by activating the death receptor pathway involving p53. Inhibition of p53 alleviated prostate cell apoptosis induced by Escherichia coli.
\end{abstract}

Correspondence to: Dr Zhigang Ji, Department of Urology, Peking Union Medical College Hospital, Chinese Academy of Medical Science, 1 Shuaifuyuan Wangfujing, Beijing 100730, P.R. China E-mail: jizigang1129@163.com

Key words: Escherichia coli, cellular tumor antigen p53, prostatitis, apoptosis

\section{Introduction}

Uropathogenic Escherichia coli (UPEC) strains are a subgroup of extra-intestinal pathogenic Escherichia coli strains, which infect extra-intestinal sites, and urinary tract infection (UTIs) are an example of the infection consequences (1). A previous study demonstrated that UPEC strains divide extraordinarily rapidly in human UTIs (2). In recent years, the association between bacterial prostatitis and UPEC has been increasingly investigated. For example, UPEC infections primarily contribute to co-resistance against fluroquinolone and $\beta$-lactams, and cause treatment complications (3). A previous animal study demonstrated a high prevalence of UPEC persistence in prostate tissue after 14 days of bacterial infection, suggesting that UPEC causes severe prostatic diseases, including prostatitis (4).

Prostatic epithelial cells are the first layer against pathogenic microorganism infection, and are exposed to inflammatory mediators and infectious cells (5). Once the prostate is infected by bacteria, including UPEC, prostate epithelial cells release inflammatory factors, and the effector cells release tumor necrosis factor, intercellular adhesion molecules and other cytokines (6). Prostate epithelial cell infection is associated with the development of prostatitis, eventually contributing to fluid imbalance (5). Prostate epithelial cell growth is an important consideration for the loss of defense function of cells in prostatitis (7). For instance, the c-Jun N-terminal kinase 2/signal transducer and activator of transcription pathway is involved in cell apoptosis; the prostate epithelial cells regulate the growth of the cells through this pathway and subsequently secrete inflammatory factors to resist the bacteria (8).

Cellular tumor antigen p53 (p53) is a well-documented anti-tumor gene and is involved in multiple cell life functions, including cell apoptosis $(9,10)$. Previous studies demonstrated that p53 alleviated mitochondrial damage induced by inflammatory-associated neurodegenerative diseases by activating the cellular inflammatory response $(11,12)$. A meta-analysis of the association between prostatitis and prostate cancer identified that prostatitis increased the risk of prostate cancer (13). In the medullary system, mild p53 activation may decrease the expression of the c-myc gene and induce mutation of the APC, WNT signaling pathway regulator gene, thus reducing the inflammatory response in mice (14). Therefore, the cells become more resistant to the development and invasion of intestinal tumors, and as a regulator of macrophage function, 
p53 serves a key role in the protection against tumors. A previous study additionally demonstrated that the p53 gene was involved in the regulation of the tumor inflammatory microenvironment, inhibited the development of inflammation and subsequently decreased the invasion of tumor cells (15). Therefore, it was hypothesized that $\mathrm{p} 53$ is closely associated with the growth of prostate epithelial cells in the bacterial prostatitis caused by UPEC. The potential use of p53 in the treatment of bacterial prostatitis was additionally considered.

In the present study, prostate epithelial cells were infected with UPEC to identify the effects of Escherichia coli on cell apoptosis and progression. Alterations in cytokine expression were additionally studied to determine the association between cell growth and cytokine expression. Furthermore, the mechanism underlying the effect of infection on apoptosis of prostate epithelial cells was examined, and the expression of apoptosis-associated proteins was assessed. The present results provide a theoretical basis for future studies on the pathogenesis of bacterial prostatitis, which may help to develop novel treatment strategies.

\section{Materials and methods}

Cells and UPEC. The prostate epithelial RWPE-1 cells, obtained from American Type Culture Collection (ATCC; Manassas, VA, USA), were cultured in keratinocyte-serum free medium (K-SFM; Life Technologies; Thermo Fisher Scientific, Inc., Waltham, MA, USA) with $0.05 \mathrm{mg} / \mathrm{ml}$ bovine pituitary extract (Life Technologies; Thermo Fisher Scientific, Inc.) and $5 \mathrm{ng} / \mathrm{ml}$ human recombinant epidermal growth factor (Life Technologies; Thermo Fisher Scientific, Inc.) in a humidified incubator with $5 \% \mathrm{CO}_{2}$ at $37^{\circ} \mathrm{C}$. The UPEC CFT073 strain was additionally obtained from ATCC (16). The CFT073 strain was cultured in lysogeny broth (Beyotime Institute of Biotechnology, Haimen, China) and ampicillin (100 $\mu \mathrm{g} / \mathrm{ml}$; Sigma-Aldrich; Merck KGaA, Darmstadt, Germany) and subsequently incubated at $37^{\circ} \mathrm{C}$ for $12 \mathrm{~h}$.

Exposure of prostate epithelial cells to UPEC and transfection. RWPE-1 cells were cultured in K-SFM and upon reaching $60 \%$ confluence, cells were starved for $24 \mathrm{~h}$ (17) to ensure that cell apoptosis and its signaling pathways were altered prior to the infection of UPEC or transfection of small interfering RNA (siRNA). The cells were transfected with Lipofectamine ${ }^{\circledR} 2000$ (Life Technologies; Thermo Fisher Scientific, Inc.). RWPE-1 cells were infected with CFT073 (multiplicity of infection of 100) and incubated at $37^{\circ} \mathrm{C}$ with $5 \% \mathrm{CO}_{2}$ for 0,12 and $24 \mathrm{~h}$. The control group cells were treated with sterile PBS. The siRNA against p53 (sense, 5'-CUACUUCCUGAAAACAAC-3'; antisense, 5'-CGUUGUUUUCAGGAAGUAG-3') and its negative control (NC; 5'-GGCTACGTCCAGGAGCGCACC-3') siRNA were purchased from Shanghai GenePharma Co., Ltd. (Shanghai, China). Cells were transfected with $50 \mathrm{nM}$ siRNA, and experiments were performed $24 \mathrm{~h}$ following transfection. The transfected cells were subsequently treated with UPEC for $12 \mathrm{~h}$ to examine the effect of silencing p53.

$R N A$ isolation and reverse transcription-quantitative polymerase chain reaction $(R T-q P C R)$. TRIzol ${ }^{\circledR}$ reagent (Invitrogen; Thermo Fisher Scientific, Inc.) was used to obtain total RNA from the cells, according to the manufacturer's protocol. The M-MLV Reverse Transcriptase (Promega Corporation, Madison, WI, USA) was utilized to synthesize cDNA from the RNA and random primers (Takara Bio, Inc., Otsu, Japan), following a standard protocol (18). qPCR was performed using an SYBR-Green kit (Takara Bio, Inc.) according to the manufacturer's protocol in an ABI-7300 system (Applied Biosystems; Thermo Fisher Scientific, Inc.). qPCR was performed as follows: $95^{\circ} \mathrm{C}$ for $30 \mathrm{sec}$, then 40 cycles of $95^{\circ} \mathrm{C}$ for $5 \mathrm{sec}$ and $60^{\circ} \mathrm{C}$ for $30 \mathrm{sec}$, and finally $61^{\circ} \mathrm{C}$ for $1 \mathrm{~min}$. The primers were purchased from Shanghai GenePharma Co., Ltd. and were used to perform the RT-qPCR, according to the manufacturer's protocol. Each PCR was replicated three times. The mRNA relative expression was measured using the $2^{-\Delta \Delta C q}$ method (19). The primer sequences used in present study are presented in Table I. GAPDH was used as the internal control.

Cell proliferation analysis. Cell proliferation was assessed by a Cell Counting Kit-8 (CCK-8; Dojindo Molecular Technologies, Inc., Kumamoto, Japan) assay and performed according to the manufacturer's protocol. A total of $5 \times 10^{3}$ cells were seeded in each well of 96-well plates treated with UPEC. The cells were exposed to UPEC for separate periods ( 0,12 and $24 \mathrm{~h}$ ). Finally, the absorbance of the treated cells was detected at $450 \mathrm{~nm}$.

Terminal deoxynucleotidyl-transferase-mediated dUTP nick end labeling (TUNEL) assay. Cells $\left(3 \times 10^{6}\right)$ were fixed at room temperature for $30 \mathrm{~min}$ with $4 \%$ paraformaldehyde. A TUNEL detection kit (Beyotime Institute of Biotechnology) was used to analyze cell apoptosis of the different treatment groups, according to the manufacturer's protocol. Cells were incubated with TUNEL reagent for $60 \mathrm{~min}$ at $37^{\circ} \mathrm{C}$ without light. DAPI $(5 \mathrm{mg} / \mathrm{ml})$ was used to stain the nuclei of the treated cells for $20 \mathrm{~min}$ at $37^{\circ} \mathrm{C}$ without light. Cells were mounted with Antifade Mounting Medium (Beyotime Institute of Biotechnology) and subsequently observed in five fields per view using a fluorescence microscope under $450-500 \mathrm{~nm}$ light (magnification, $\mathrm{x} 40$ ).

Flow cytometry analysis. Pre-treated cells $\left(2 \times 10^{6}\right)$ were enriched from cell petri dishes and washed twice with cold PBS to remove floating cells. An Annexin V-Fluorescein Isothiocyanate Apoptosis Detection kit (Nanjing KeyGen Biotech Co., Ltd., Nanjing, China) was used to detect the cell apoptosis rate. Apoptosis was measured using a flow cytometer (BD Biosciences, San Jose, CA, USA) and BD CellQuest ${ }^{\mathrm{TM}}$ version 2.0 software (BD Biosciences).

Western blot analysis. RWPE-1 cells treated with UPEC or p53 siRNA were lysed for 30 min with lysis buffer (Beyotime Institute of Biotechnology) on ice and subsequently centrifuged at $4^{\circ} \mathrm{C}$ and $100 \mathrm{x} \mathrm{g}$ for $15 \mathrm{~min}$. A bicinchoninic acid protein assay kit (Beyotime Institute of Biotechnology) was used to evaluate the concentration of extracted protein. The different sized proteins ( $20 \mu 1 /$ lane) were separated using $10 \%$ SDS-PAGE and the bands were transferred to polyvinylidene fluoride membranes (EMD Millipore, Billerica, MA, USA). The membranes were blocked with $5 \%$ skimmed milk powder at room temperature for $1 \mathrm{~h}$ and incubated with primary antibodies overnight at $4^{\circ} \mathrm{C}$. The following antibodies from 
Table I. Primers sequences used for polymerase chain reaction.

\begin{tabular}{lll}
\hline Gene & \multicolumn{1}{c}{ Sense primer $\left(5^{\prime} \rightarrow 3^{\prime}\right)$} & Antisense primer $\left(5^{\prime} \rightarrow 3^{\prime}\right)$ \\
\hline p53 & TCGCTGCGAAGGACATTTGGG & AGCGACGCTTCCTGTAAACCC \\
Bax & GGGAGCCAAATGCTTTGCTAG & CCCTCGGTTTACGAAACGATC \\
Caspase-9 & AGGACTCAAATTCTGTTGCCACC & AGGACTCAAATTCTGTTGCCACC \\
Caspase-3 & TGGAACAAATGGACCTGTTGACC & AGGACTCAAATTCTGTTGCCACC \\
GAPDH & CGGAGTCAACGGATTTGGTCGTAT & AGCCTTCTCCATGGTGGTGAAGAC
\end{tabular}

p53, cellular tumor antigen p53; Bax, apoptosis regulator BAX.

Santa Cruz Biotechnology, Inc. (Dallas, TX, USA) were used: Apoptosis regulator BAX (Bax; 1:1,000; sc-20067); p53 (1:1,000; sc-47698); protein kinase B (Akt; 1:1,000; sc-24500); phosphorylated (p)-Akt (1:1,000; sc-33437) and $\beta$-actin (1:500; sc-517582). Subsequently, membranes were incubated with horseradish peroxidase-conjugated secondary antibodies (goat anti-rat immunoglobulin G, 1:1,000; A0192, and goat anti-rabbit immunoglobulin G; 1:1,000; A0208; Beyotime Institute of Biotechnology) for $1.5 \mathrm{~h}$ at room temperature. Each protein of interest was detected using enhanced chemiluminescence reagent (Beyotime Institute of Biotechnology).

Cytokine assay. Following treatment with UPEC, cytokines secreted by RWPE-1 cells into the culture medium were determined by ELISAs (Human IL-4 Quantikine ELISA Kit, S4050; Human IL-6 Quantikine ELISA Kit, SS600C; Human IL-8/CXCL8 Quantikine ELISA Kit, S8000C; Human IL-10 Quantikine ELISA Kit, S1000B; all from R\&D Systems, Inc., Minneapolis, MN, USA) or MILLIPLEX MAP Human Cytokine/Chemokine Magnetic Bead multiplex assay (EMD Millipore) according to the manufacturer's protocol.

Statistical analysis. All assays were conducted at least three times independently. The data are presented as the mean \pm standard deviation, and comparisons among different treated groups were analyzed by one-way analysis of variance followed by Student-Newman-Keuls test using SPSS 13.0 (SPSS, Inc., Chicago, IL, USA). P $<0.05$ was considered to indicate a statistically significant difference.

\section{Results}

Apoptotic rate of RWPE-1 cells is increased by infection with UPEC. The apoptosis rate of prostatic epithelial RWPE-1 cells treated with UPEC was analyzed by flow cytometry and TUNEL assays. The cell apoptosis rates were 9.8, 15.4 and $24.9 \%$ at 0,12 and $24 \mathrm{~h}$, respectively, demonstrated by the flow cytometry assay. The apoptosis rate at $12 \mathrm{~h}$ and $24 \mathrm{~h}$ was significantly higher compared with at $0 \mathrm{~h}(\mathrm{P}<0.05$; Fig. $1 \mathrm{~A}$ and $\mathrm{B})$. The TUNEL assay confirmed that cell apoptosis at $12 \mathrm{~h}$ and $24 \mathrm{~h}$ increased compared with at $0 \mathrm{~h}$ following treatment with UPEC (Fig. 1C).

Alterations of p53, Bax, caspase-9 and caspase-3 expression in prostatic epithelial cells infected with UPEC. Alterations in the expression of apoptosis-associated proteins, due to the effect of UPEC on apoptosis rates, of RWPE-1 cells were measured. The expressions of p53, Bax, caspase- 9 and caspase- 3 mRNA were examined by RT-qPCR. It was identified that the mRNA expression levels of p53 and Bax were increased upon exposure to UPEC in a time-dependent manner (Fig. 2A and B). Additionally, the transcriptional expression level of caspase-9 and caspase-3 demonstrated similar trends (Fig. 2C and D). Furthermore, western blotting demonstrated that p53 and Bax protein expressions were upregulated upon infection with UPEC (Fig. 2E).

Proliferation of RWPE-1 cells is inhibited by infection with UPEC. The proliferation of RWPE-1 cells infected with UPEC was assessed by a CCK-8 assay. Optical density values at $450 \mathrm{~nm}$ demonstrated differences in the proliferation of prostate epithelial RWPE-1 cells treated with UPEC for 12 and $24 \mathrm{~h}$ compared with $0 \mathrm{~h}$ in the CCK- 8 assay; as the treatment time increased, the proliferative ability of RWPE-1 cells at $96 \mathrm{~h}$ significantly decreased $(\mathrm{P}<0.05$; Fig. 3A). Infection of UPEC additionally led to a downregulation of Akt protein expression and promotion of p-Akt expression (Fig. 3B).

UPEC infection promotes secretion of IL-4, IL-6 and IL-8, and inhibits $I L-10$ secretion. Cell growth and apoptosis are closely associated with the secretion of ILs (20). Therefore, alterations in the expression levels of ILs secreted by the cells were studied, as an increase in the rate of apoptosis was observed in prostatic epithelial cells infected with UPEC. The concentrations of IL-4, IL-6, IL-8 and IL-10 in the supernatant of cultured prostatic epithelial cells were examined. As the incubation time with UPEC increased, the concentrations of IL-4, IL-6 and IL- 8 increased. The concentrations of IL-4, IL- 6 and IL-8 were significantly increased at 12 and $24 \mathrm{~h}$, compared with at $0 \mathrm{~h}(\mathrm{P}<0.05$; Fig. 4A-C). However, the concentration of IL-10 decreased as the UPEC stimulation time increased. The concentration of IL-10 was significantly decreased at 12 and $24 \mathrm{~h}$, compared with at $0 \mathrm{~h}(\mathrm{P}<0.05$; Fig. 4D).

Inhibition of p53 alleviates prostatic epithelial cell apoptosis induced by UPEC. siRNA of p53 was used to suppress the expression level of p53 in prostatic epithelial cells and to examine the mechanism of UPEC-induced apoptosis in prostatic epithelial cells. The expression of p53 in the siRNA group was decreased compared with the siRNA negative group following treatment with p53 siRNA (Fig. 5A). The apoptosis rates of the UPEC+siRNA group and PBS+siRNA 
A

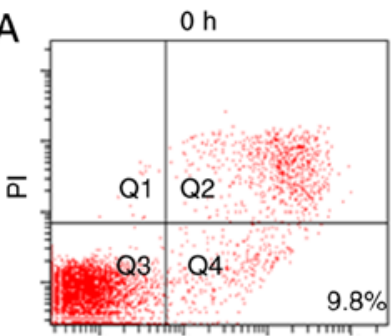

FITC
$12 \mathrm{~h}$

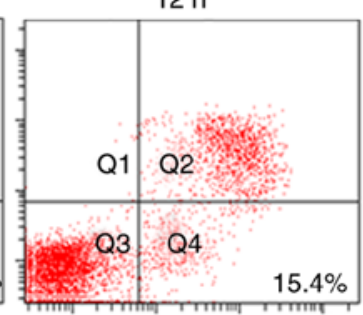

FITC
$24 \mathrm{~h}$

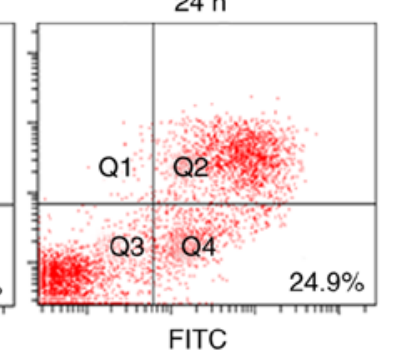

FITC
B

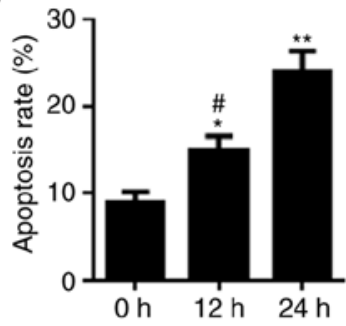

C
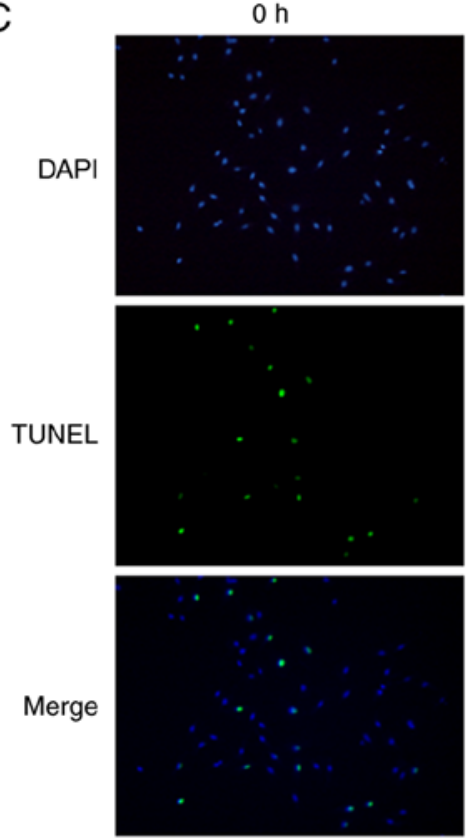

$12 \mathrm{~h}$
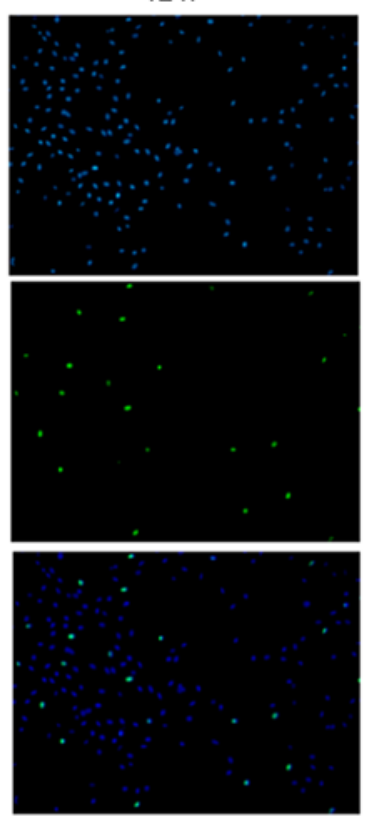

$24 \mathrm{~h}$
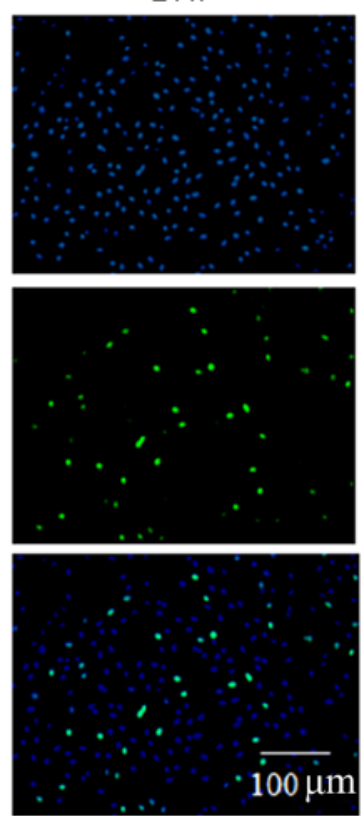

Figure 1. Escherichia coli infection promotes apoptosis of RWPE-1 cells. (A) Flow cytometric plots and (B) quantification demonstrated that the apoptosis rates increased in prostatic epithelial cells. ${ }^{*} \mathrm{P}<0.05,{ }^{* *} \mathrm{P}<0.01$ vs. $0 \mathrm{~h}$ group; ${ }^{*} \mathrm{P}<0.05$ vs. $24 \mathrm{~h}$ group. (C) TUNEL assay detected cell apoptosis of RWPE-1 treated with uropathogenic Escherichia coli for 0, 12 and 24 h. Data are presented as the mean \pm standard deviation. TUNEL, terminal deoxynucleotidyl-transferase-mediated dUTP nick end labeling; PI, propidium iodide; FITC, fluorescein isothiocyanate; Q, quadrant.

group demonstrated significant decreases compared with the UPEC+NC group, following treatment with UPEC for $12 \mathrm{~h}$ $(\mathrm{P}<0.01$; Fig. 5B and $\mathrm{C})$. The TUNEL assay additionally demonstrated that transfection with p53 siRNA alleviated RWPE-1 apoptosis induced by infection with UPEC (Fig. 5D). It was demonstrated that the expression levels of IL-4 and IL-6 were modulated by p53 inhibition when the RWPE-1 cells were infected with UPEC (Fig. 5E and F). In addition, when the expression of p53 was inhibited, the expression of apoptosis-associated proteins was downregulated compared with the UPEC+NC group (Fig. 5G).

\section{Discussion}

Escherichia coli has been identified as a part of the normal intestinal flora; however, alterations in its location and number of bacteria are likely to cause disease, particularly inflammation. Escherichia coli infection causes acute lung injury (21), diarrhea (22), pelvic inflammatory (23) and other diseases. UTIs are the second most common infectious diseases following respiratory infection (24), and is additionally closely associated with Escherichia coli. A previous study observed that $>95 \%$ of UTIs were caused by single bacteria, of which $90 \%$ were UTIs caused by Escherichia coli (25). UPEC is able to produce a number of different virulence factors, including toxins, adhesins and siderophore receptors (26). Following contact with the host organism, these virulence factors serve a critical role by coordinating with each other to avoid and antagonize the immune attacks of the host, and to invade, proliferate and infringe on the host organism (27). In addition, the effect of Escherichia coli infection on the infected cells is to enhance the apoptosis of cells (28). Therefore, the aim of the present study was to investigate the effect of Escherichia coli on the growth of prostate epithelial cells.

p53 is a tumor suppressor gene that has been widely studied and has numerous functions. It is involved in the regulation of various cell activities, including the occurrence (29), development (30), apoptosis and metastasis (31) of cancer cells. A previous study demonstrated that the p53 gene in prostate cancer cells was activated, and patients with prostate cancer demonstrated a better response to treatment (32). In addition, p53 serves a significant role in cellular inflammation. In the process of Mycobacterium tuberculosis infection, p53 may serve as a vector for microRNA to regulate the apoptosis of infected cells and serve an important regulatory role (33). A previous study additionally identified that p53 gene expression increased in prostatitis, particularly in acute prostatitis (34). Due to the increased expression of p53 in inflammation and 
A

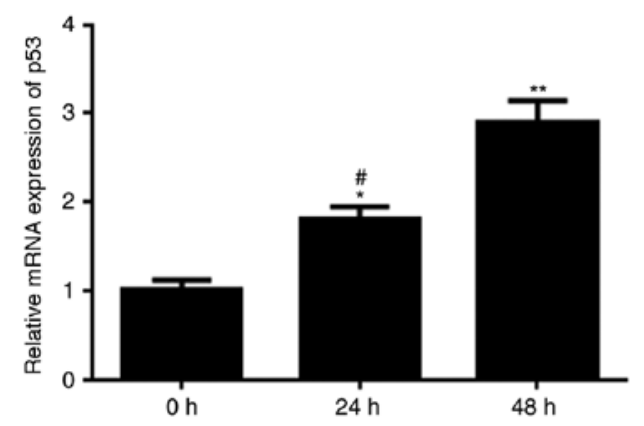

C

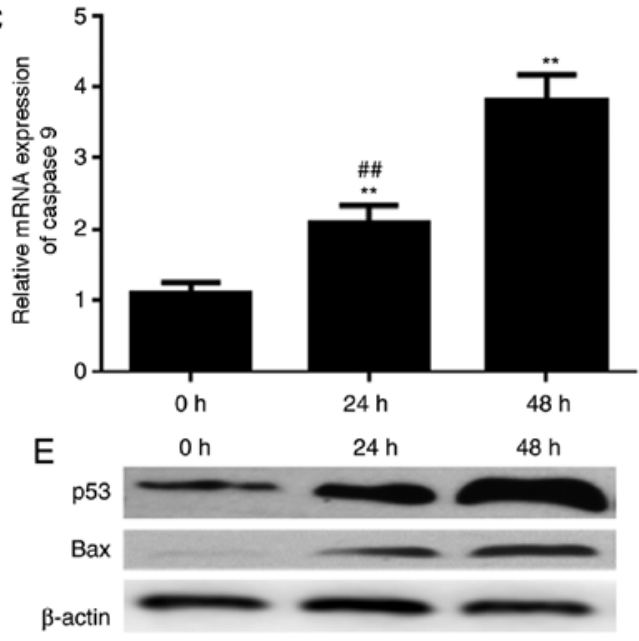

B

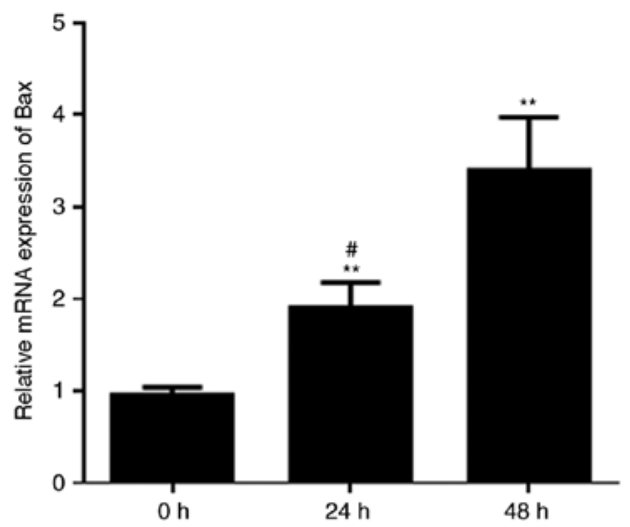

D

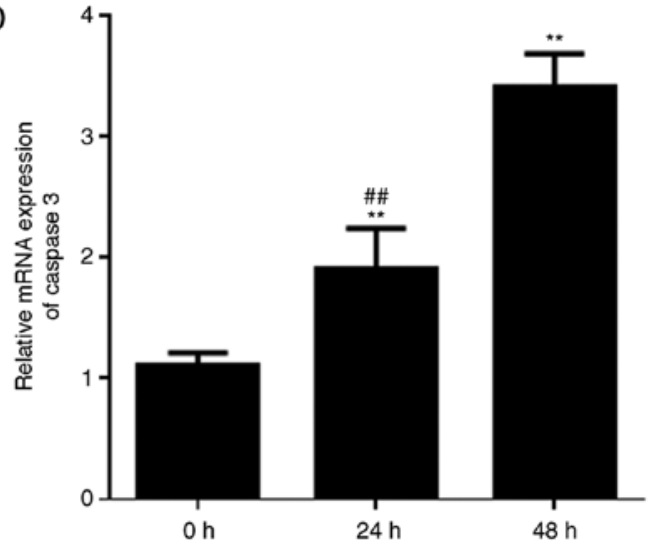

Figure 2. mRNA expression level of p53, Bax, caspase-9 and caspase-3 in prostatic epithelial cells following UPEC infection. (A) p53, (B) Bax, (C) caspase-9 and (D) caspase- 3 mRNA expression of RWPE-1 detected by reverse transcription-quantitative polymerase chain reaction. ${ }^{*} \mathrm{P}<0.05$, ${ }^{* *} \mathrm{P}<0.01 \mathrm{vs} .0 \mathrm{~h}$ group; ${ }^{\#} \mathrm{P}<0.05,{ }^{\# \#} \mathrm{P}<0.01$ vs. $48 \mathrm{~h}$ group. (E) Protein expression of p53 and Bax of RWPE-1 treated with UPEC were detected by western blotting. Data are presented as the mean \pm standard deviation. p53, cellular tumor antigen p53; Bax, apoptosis regulator BAX; UPEC, uropathogenic Escherichia coli.
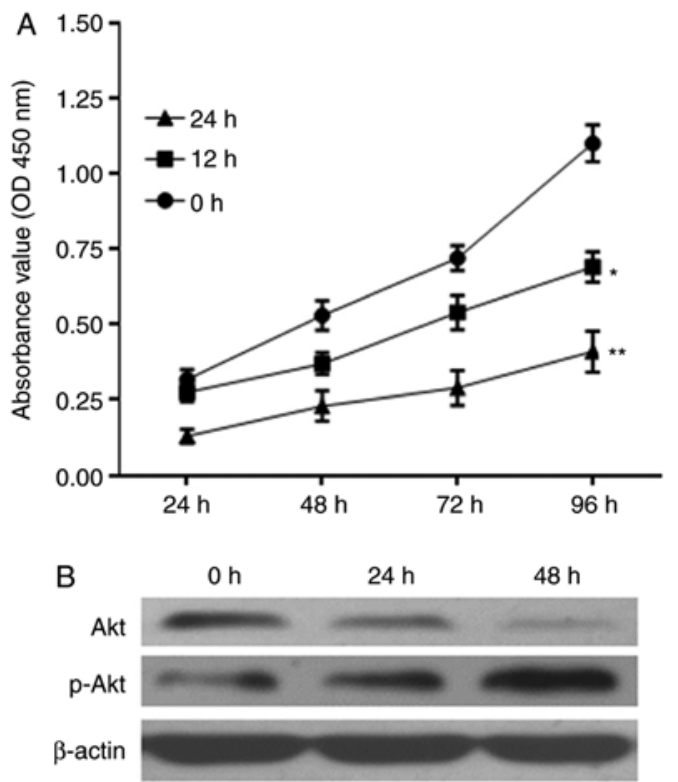

Figure 3. Escherichia coli infection suppresses proliferation of prostatic epithelial cells. (A) Proliferation of RWPE-1 was inhibited by Escherichia coli demonstrated by a Cell Counting Kit- 8 assay. ${ }^{*} \mathrm{P}<0.05,{ }^{* *} \mathrm{P}<0.01$ vs. $0 \mathrm{~h}$ group. (B) Expression of Akt and p-Akt protein following uropathogenic Escherichia coli infection was detected by western blotting. Data are presented as the mean \pm standard deviation. Akt, protein kinase B; p, phosphorylated; OD, optical density. prostatitis caused by bacterial infection, the function of p53 in the process of inflammation was examined in the present study.

The regulation between pro-inflammatory factors, including tumor necrosis factor, IL-4, IL-6 and IL-8, and anti-inflammatory factors, including IL-10, is necessary in order to balance the immune response (35). In addition, cytokines serve an important role in cell signaling transmission, including inflammatory reactions and apoptosis (36). A previous study identified that infection with Mycoplasma pneumonia resulted in an imbalance in the inflammatory response, leading to the conversion of apoptosis to cell death, and ultimately resulting in more severe pulmonary inflammation (37). The high expression level of IL- 6 demonstrates a close association between inflammation and cell survival, and IL-6 inhibits apoptosis by regulating hallmarks in inflammation and multiple signaling pathways $(18,38)$. At the prostatitis stage, cytokines associated with inflammation, including the expression level of IL-10, may be indicators for the treatment course of patients (39). It was identified that ILs are involved in the apoptosis pathway. For example, IL-10 gene silencing caused downregulation of phosphoinositide 3-kinase/Akt and B cell lymphoma-2 (Bcl-2) gene expression, and increases the Bcl-2-binding component 3 , Bax, caspase-3 and caspase-3 cleavage expression levels, to regulate the apoptosis of breast cancer cells (40). Therefore, it was hypothesized that the secretion of ILs by the 

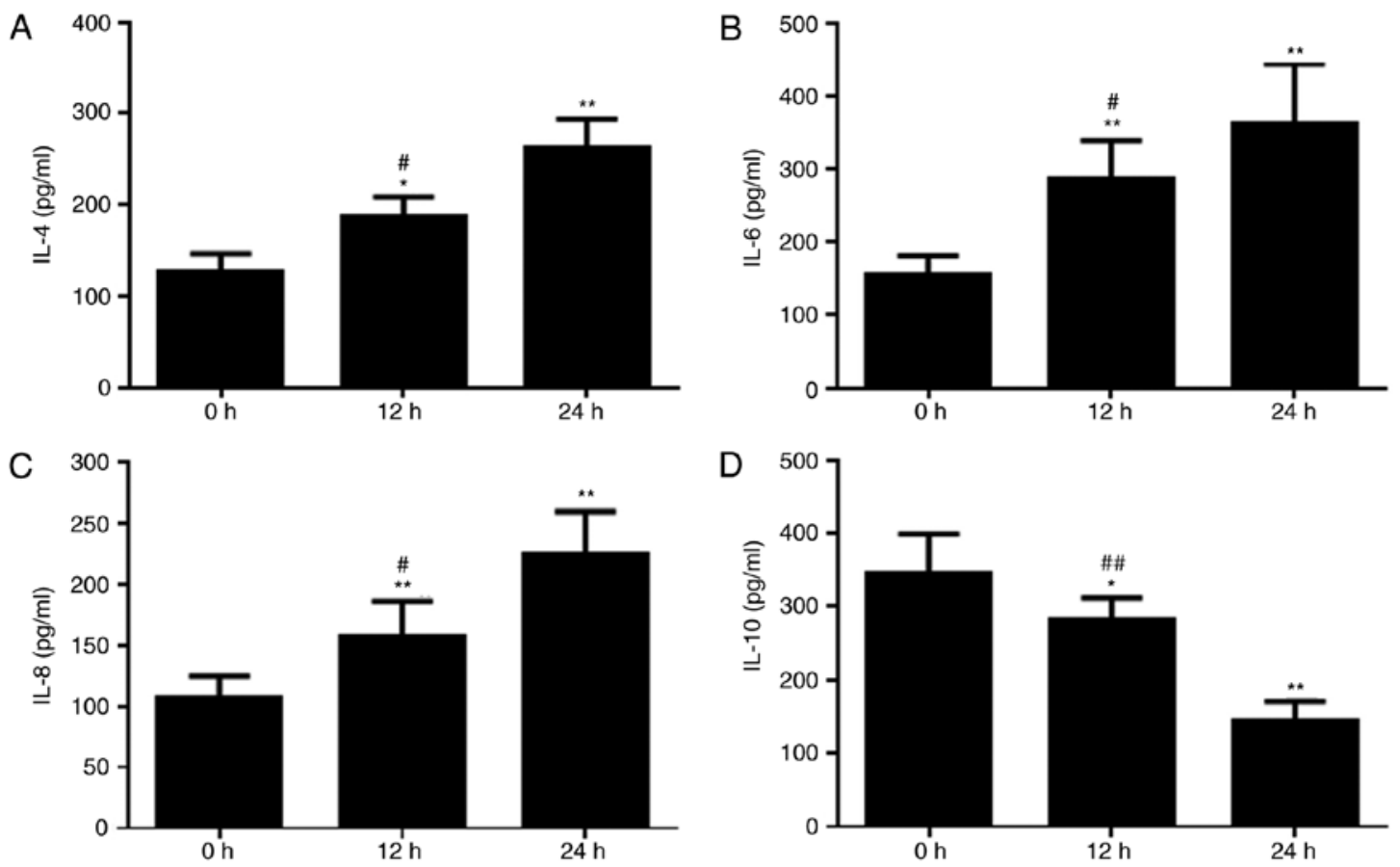

Figure 4. Escherichia coli infection alters the secretion level of prostatic epithelial cells. Expression levels of (A) IL-4, (B) IL-6 and (C) IL-8 were increased by treatment with UPEC. (D) Expression level of IL-10 was decreased by treatment with UPEC. Data are presented as the mean \pm standard deviation. "P $<0.05$, ${ }^{* * *} \mathrm{P}<0.01$ vs. 0 h group; ${ }^{\# \mathrm{P}}<0.05,{ }^{\# \#} \mathrm{P}<0.01$ vs. 24 h group. IL, interleukin; UPEC, uropathogenic Escherichia coli.
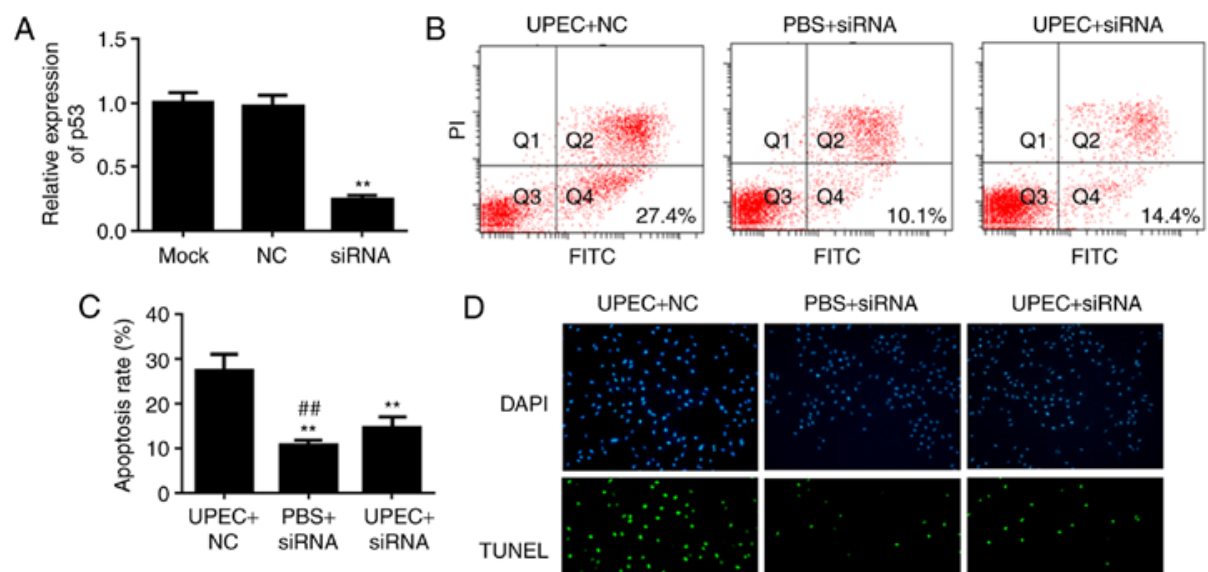

D
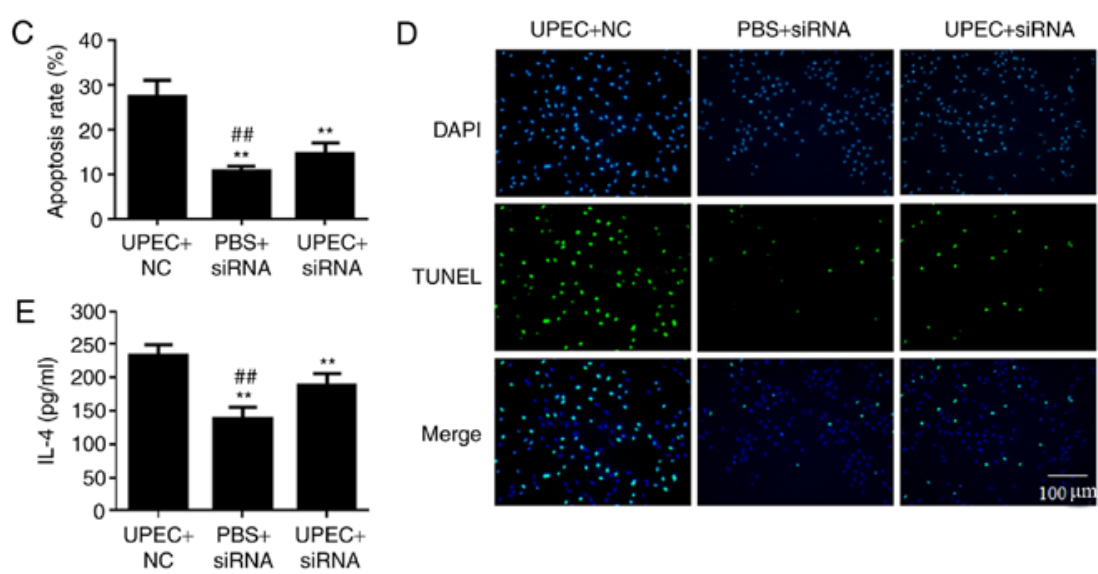

TUNEL
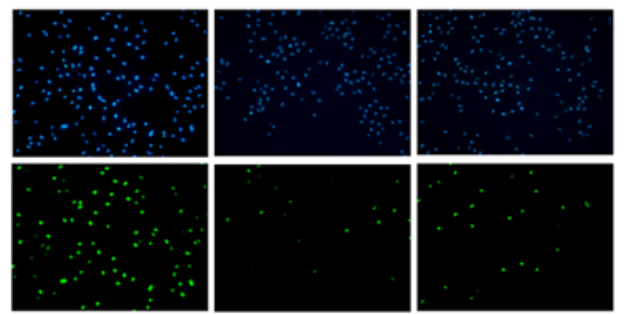

Merge
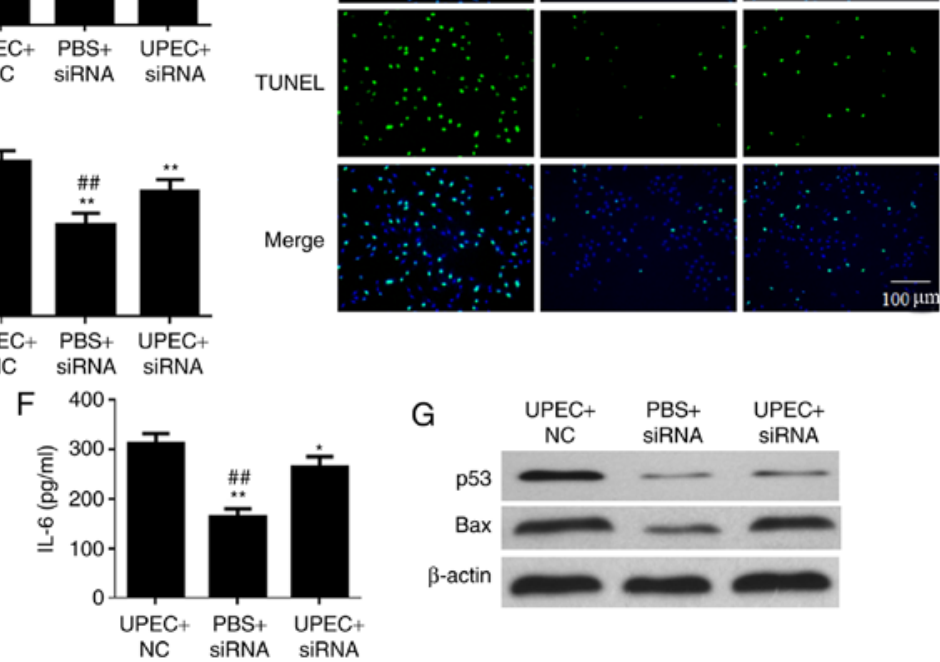

Figure 5. Inhibition of p53 gene expression alleviates the apoptosis of prostatic epithelial cells caused by Escherichia coli infection. (A) siRNA inhibits p53 gene expression. ${ }^{* *} \mathrm{P}<0.01$ vs. NC. Apoptosis rate of RWPE-1 cells was determined by (B) flow cytometric plots and (C) analysis. (D) TUNEL assay detected the cell apoptosis of RWPE-1 cells. Expression levels of (E) IL-4 and (F) IL-6 were affected by UPEC and p53 siRNA detected by ELISA. "P<0.05, ${ }^{* *} \mathrm{P}<0.01$ vs. UPEC+NC; ${ }^{\# \#} \mathrm{P}<0.01$ vs. UPEC+siRNA. Data are presented as the mean \pm standard deviation. (G) Protein expression of p53 and Bax under treatment with UPEC and transfection of p53 siRNA were detected by western blotting. siRNA, small interfering RNA; p53, cellular tumor antigen p53; NC, negative control; UPEC, uropathogenic Escherichia coli; TUNEL, terminal deoxynucleotidyl-transferase-mediated dUTP nick end labeling; IL, interleukin; Bax, apoptosis regulator BAX; PI, propidium iodide; FITC, fluorescein isothiocyante; Q, quadrant. 
prostate epithelial cells may alter subsequent to transfection with siRNA against p53, alleviating the apoptosis of prostate epithelial cells induced by UPEC.

The effect of UPEC on prostatic epithelial cell apoptosis was investigated. Flow cytometry and a TUNEL assay demonstrated that UPEC infection promoted the apoptosis of prostate epithelial RWPE-1 cells. The western blotting and RT-qPCR assay determined the effect of UPEC infection of RWPE-1 cell apoptosis-associated proteins, and demonstrated that the mRNA and protein of p53 and Bax expression were increased. In addition, the mRNA expression levels of caspase- 9 and caspase-3 were upregulated under treatment with UPEC. The proliferation of prostate epithelial cells decreased as a result, and the progression of bacterial prostatitis was promoted by UPEC infection. The progression of prostatitis inflammation was additionally regulated by altering the secretion of IL-4 IL-6, IL-8 and IL-10 following UPEC infection; however, due to experimental limitations, the effects of p53 downregulation on the expression of all ILs were not fully investigated. Therefore, additional experiments are required to provide further insight into the roles of p53 and IL signaling in prostatic epithelial cells following UPEC infection.

When siRNA against p53 gene was transfected, the ILs secreted by prostatitis cells altered, suggesting that siRNA of p53 alleviated the damage of UPEC on the prostate cells. Furthermore, when the p53 gene, which is closely associated with the apoptotic process, was inhibited by siRNA, the pro-apoptotic effect of UPEC on prostate RWPE-1 cells was alleviated. Following infection with UPEC, the apoptosis of prostate epithelial cells was increased. However, the apoptosis of prostate epithelial cells was decreased upon p53 gene silencing. Therefore, it was hypothesized that the p53 gene is one of the key genes in UPEC infection of prostate epithelial cells and the formation of bacterial prostatitis, which additionally promoted the apoptosis of RWPE-1 cells. All the present results demonstrated that inhibition of p53 gene expression alleviated the apoptosis of bacterial prostatitis cells, which additionally provides novel insight for the development of treatments for bacterial prostatitis caused by UPEC.

\section{Acknowledgements}

Not applicable.

\section{Funding}

The present study was supported by the Basic Research Projects of Beijing (grant no. 2016B032; China).

\section{Availability of data and materials}

The datasets used and/or analyzed during the current study are available from the corresponding author on reasonable request.

\section{Authors' contributions}

ZJ designed the study, and HW performed the experiments and statistical analysis. All authors read and approved the final manuscript.

\section{Ethics approval and consent to participate}

Not applicable.

\section{Patient consent for publication}

Not applicable.

\section{Competing interests}

The authors declare that they have no competing interests.

\section{References}

1. Ali I, Shabbir M and Noor U1 I: Antibiotics susceptibility patterns of uropathogenic E. coli with special reference to fluoroquinolones in different age and gender groups. J Pak Med Assoc 67: 1161-1165, 2017.

2. Forsyth VS, Armbruster CE, Smith SN, Pirani A, Springman AC, Walters MS, Nielubowicz GR, Himpsl SD, Snitkin ES and Mobley HL: Rapid growth of uropathogenic Escherichia coli during human urinary tract infection. MBio 9: pii: e00186-18, 2018.

3. Basu S and Mukherjee M: Incidence and risk of co-transmission of plasmid-mediated quinolone resistance and extended-spectrum $\beta$-lactamase genes in fluoroquinolone-resistant uropathogenic Escherichia coli: A first study from Kolkata, India. J Glob Antimicrob Resist 14: 217-223, 2018.

4. Boehm BJ, Colopy SA, Jerde TJ, Loftus CJ and Bushman W: Acute bacterial inflammation of the mouse prostate. Prostate 72: 307-317, 2012.

5. Seo MY, Im SJ, Gu NY, Kim JH, Chung YH, Ahn MH and Ryu JS: Inflammatory response of prostate epithelial cells to stimulation by Trichomonas vaginalis. Prostate 74: 441-449, 2014.

6. Longhi C, Comanducci A, Riccioli A, Ziparo E, Marazzato M, Aleandri M, Conte AL, Lepanto MS, Goldoni P and Conte MP: Features of uropathogenic Escherichia coli able to invade a prostate cell line. New Microbiol 39: 146-149, 2016

7. Wagenlehner FM, Pilatz A, Bschleipfer T, Diemer T, Linn T, Meinhardt A, Schagdarsurengin U, Dansranjavin T, Schuppe HC and Weidner W: Bacterial prostatitis. World J Urol 31: 711-716, 2013.

8. Ho CH, Fan CK, Yu HJ, Wu CC, Chen KC, Liu SP and Cheng PC: Testosterone suppresses uropathogenic Escherichia coli invasion and colonization within prostate cells and inhibits inflammatory responses through JAK/STAT-1 signaling pathway. PLoS One 12: $\mathrm{e} 0180244,2017$

9. Bilancio A, Bontempo P, Di Donato M, Conte M, Giovannelli P, Altucci L, Migliaccio A and Castoria G: Bisphenol A induces cell cycle arrest in primary and prostate cancer cells through EGFR/ERK/p53 signaling pathway activation. Oncotarget 8: 115620-115631, 2017.

10. Hong SH, Lee DH, Lee YS, Jo MJ, Jeong YA, Kwon WT, Choudry HA, Bartlett DL and Lee YJ: Molecular crosstalk between ferroptosis and apoptosis: Emerging role of ER stress-induced p53-independent PUMA expression. Oncotarget 8: 115164-115178, 2017.

11. Choi SE, Park YS and Koh HC: NF- $\kappa$ B/p53-activated inflammatory response involves in diquat-induced mitochondrial dysfunction and apoptosis. Environ Toxicol 33: 1005-1018, 2018.

12. Siegl C and Rudel T: Modulation of p53 during bacterial infections. Nat Rev Microbiol 13: 741-748, 2015.

13. Perletti G, Monti E, Magri V, Cai T, Cleves A, Trinchieri A and Montanari E: The association between prostatitis and prostate cancer. Systematic review and meta-analysis. Arch Ital Urol Androl 89: 259-265, 2017.

14. He XY, Xiang C, Zhang CX, Xie YY, Chen L, Zhang GX, Lu Y and Liu G: p53 in the myeloid lineage modulates an inflammatory microenvironment limiting initiation and invasion of intestinal tumors. Cell Rep 13: 888-897, 2015.

15. Uehara I and Tanaka N: Role of p53 in the regulation of the inflammatory tumor microenvironment and tumor suppression. Cancers (Basel) 10: E219, 2018. 
16. Saldaña Z, De la Cruz MA, Carrillo-Casas EM, Durán L, Zhang Y, Hernández-Castro R, Puente JL, Daaka Y and Girón JA: Production of the Escherichia coli common pilus by uropathogenic E. coli is associated with adherence to HeLa and HTB-4 cells and invasion of mouse bladder urothelium. PLoS One 9: e101200, 2014.

17. Shen XF, Ren LB, Teng Y, Zheng S, Yang XL, Guo XJ, Wang XY, Sha KH, Li N, Xu GY, et al: Luteolin decreases the attachment, invasion and cytotoxicity of UPEC in bladder epithelial cells and inhibits UPEC biofilm formation. Food Chem Toxicol 72 204-211, 2014.

18. Xu SY, Huang X and Cheong KL: Recent advances in marine algae polysaccharides: Isolation, structure and activities. Mar Drugs 15: E388, 2017.

19. Livak KJ and Schmittgen TD: Analysis of relative gene expression data using real-time quantitative PCR and the 2(-Delta Delta $\mathrm{C}(\mathrm{T})$ ) method. Methods 25: 402-408, 2001.

20. Nicholl MB, Ledgewood CL, Chen X, Bai Q, Qin C, Cook KM, Herrick EJ, Diaz-Arias A, Moore BJ and Fang Y: IL-35 promotes pancreas cancer growth through enhancement of proliferation and inhibition of apoptosis: Evidence for a role as an autocrine growth factor. Cytokine 70: 126-133, 2014.

21. Curley GF, Jerkic M, Dixon S, Hogan G, Masterson C, O'Toole D, Devaney J and Laffey JG: Cryopreserved, xeno-free human umbilical cord mesenchymal stromal cells reduce lung injury severity and bacterial burden in rodent Escherichia coli-induced acute respiratory distress syndrome. Crit Care Med 45: e202-e212, 2017.

22. Ercumen A, Arnold BF, Naser AM, Unicomb L, Colford JM Jr and Luby SP: Potential sources of bias in the use of Escherichia coli to measure waterborne diarrhoea risk in low-income settings. Trop Med Int Health 22: 2-11, 2017.

23. Kow N, Holthaus E and Barber MD: Bacterial uropathogens and antibiotic susceptibility of positive urine cultures in women with pelvic organ prolapse and urinary incontinence. Neurourol Urodyn 35: 69-73, 2016.

24. Magistro G, Marcon J, Schubert S, Gratzke C and Stief CG: Pathogenesis of urinary tract infections: An update. Urologe A 56: 720-727, 2017 (In German).

25. Tarchouna M, Ferjani A, Ben-Selma W and Boukadida J: Distribution of uropathogenic virulence genes in Escherichia coli isolated from patients with urinary tract infection. Int $\mathrm{J}$ Infect Dis 17: e450-e453, 2013.

26. Terlizzi ME, Gribaudo G and Maffei ME: UroPathogenic Escherichia coli (UPEC) infections: Virulence factors, bladder responses, antibiotic, and non-antibiotic antimicrobial strategies Front Microbiol 8: 1566, 2017.

27. Johnson JR, Jelacic S, Schoening LM, Clabots C, Shaikh N, Mobley HL and Tarr PI: The IrgA homologue adhesin Iha is an Escherichia coli virulence factor in murine urinary tract infection. Infect Immun 73: 965-971, 2005.
28. Eskandari M, Jani S, Kazemi M, Zeighami H, Yazdinezhad A, Mazloomi S and Shokri S: Ameliorating effect of ginseng on epididymo-orchitis inducing alterations in sperm quality and spermatogenic cells apoptosis following infection by uropathogenic Escherichia coli in rats. Cell J 18: 446-457, 2016.

29. Semczuk A, Ignatov A, Obrzut B, Reventos J and Rechberger T: Role of p53 pathway alterations in uterine carcinosarcomas (malignant mixed Müllerian tumors). Oncology 87: 193-204, 2014

30. Xie $\mathrm{H}$ and Wang H: PRL-3 promotes breast cancer progression by downregulating p14 ${ }^{\mathrm{ARF}}$-mediated $\mathrm{p} 53$ expression. Oncol Lett 15: 2795-2800, 2018

31. Ali AS, Grönberg M, Federspiel B, Scoazec JY, Hjortland GO, Grønbæk H,Ladekarl M,Langer SW, Welin S, Vestermark LW, etal: Expression of p53 protein in high-grade gastroenteropancreatic neuroendocrine carcinoma. PLoS One 12: e0187667, 2017.

32. Chopra H, Khan Z, Contreras J, Wang H, Sedrak A and Zhu Y: Activation of $\mathrm{p} 53$ and destabilization of androgen receptor by combinatorial inhibition of MDM2 and MDMX in prostate cancer cells. Oncotarget 9: 6270-6281, 2017.

33. Liang S, Song Z, Wu Y, Gao Y, Gao M, Liu F, Wang F and Zhang Y: MicroRNA-27b modulates inflammatory response and apoptosis during Mycobacterium tuberculosis infection. J Immunol 200: 3506-3518, 2018.

34. Wang W, Bergh A and Damber JE: Increased p53 immunoreactivity in proliferative inflammatory atrophy of prostate is related to focal acute inflammation. APMIS 117: 185-195, 2009.

35. Liu Y, Shi B, Li Y and Zhang H: Protective effect of luteolin against renal ischemia/reperfusion injury via modulation of pro-inflammatory cytokines, oxidative stress and apoptosis for possible benefit in kidney transplant. Med Sci Monit 23: 5720-5727, 2017.

36. Li L, Wang B, Yu P, Wen X, Gong D and Zeng Z: Medium and long chain fatty acids differentially modulate apoptosis and release of inflammatory cytokines in human liver cells. J Food Sci 81: H1546-H1552, 2016.

37. Bai F, Ni B, Liu M, Feng Z, Xiong Q and Shao G: Mycoplasma hyopneumoniae-derived lipid-associated membrane proteins induce inflammation and apoptosis in porcine peripheral blood mononuclear cells in vitro. Vet Microbiol 175: 58-67, 2015.

38. Kumari N, Dwarakanath BS, Das A and Bhatt AN: Role of interleukin-6 in cancer progression and therapeutic resistance. Tumour Biol 37: 11553-11572, 2016.

39. La Vignera S, Calogero AE, Castiglione R, D'Agata R, Giammusso B, Condorelli R and Vicari E: IL-6, TNFalfa, IL-10 in the seminal plasma of patients with bacterial male accessory gland infections after sequential therapy. Minerva Urol Nefrol 60: 141-145, 2008.

40. Alotaibi MR, Hassan ZK, Al-Rejaie SS, Alshammari MA, Almutairi MM, Alhoshani AR, Alanazi WA, Hafez MM and Al-Shabanah OA: Characterization of apoptosis in a breast cancer cell line after IL-10 silencing. Asian Pac J Cancer Prev 19: 777-783, 2018. 